DR LIISA ANNELI KANTOJÄRVI (Orcid ID : 0000-0002-0426-2601)

Article type : Original Article

\title{
Personality Disorders of drivers killed in fatal motor vehicle accidents in Finland during 1990-2011
}

Running title: Drivers with personality disorder

Räisänen Tuija, MD ${ }^{\text {a }}$, Hakko Helinä, $\mathrm{PhD}^{\mathrm{a}}$, Riipinen Pirkko, MD, PhD, ${ }^{\mathrm{b}}$ Räty Esa, MSc

(Technology) ${ }^{\mathrm{c}}$, Kantojärvi Liisa $\mathrm{MD}, \mathrm{PhD}^{\mathrm{a}}$

${ }^{a}$ Oulu University Hospital, Department of Psychiatry, Finland

Address: P.O. BOX 26, FIN 90029 OYS, Finland

e-mail: tuija.i.raisanen@pphsp.fi, helina.hakko@ppshp.fi, liisa.kantojarvi@oulu.fi

${ }^{\mathrm{b}}$ Department of Psychiatry, Research Unit of Clinical Neuroscience, University of Oulu

Address: P.O. BOX 5000, FIN 90014 OYS, Finland

e-mail:pirkko.riipinen@oulu.fi

${ }^{\mathrm{c}}$ The Finnish Crash Data Institute OTI

Address: Itämerenkatu 11-13, FI-00180 Helsinki, Finland

e-mail:esa.raty@oti.fi

Corresponding author: $\quad$ MD, PhD Kantojärvi Liisa

Department of Psychiatry, Research Unit of Clinical Neuroscience, University of Oulu

P.O. Box 5000, FIN-90014 University of Oulu, Finland

This article has been accepted for publication and undergone full peer review but has not been through the copyediting, typesetting, pagination and proofreading process, which may lead to differences between this version and the Version of Record. Please cite this article as doi: 10.1111/acps.13039

This article is protected by copyright. All rights reserved. 
Tel: +358-8-3156800; Fax: +358-8-333 167

Email: liisa.kantojarvi@oulu.fi

\begin{abstract}
Objective: To examine the association of personality disorders (PDs) to deaths of drivers in fatal motor vehicle accidents, and analyse gender differences in lifetime psychiatric disorders and medico-legal findings at the time of accident.
\end{abstract}

Methods: The study sample consisted of 4,810 Finnish drivers killed in fatal motor vehicle accidents in Finland between 1990 and 2011. Doctor-diagnosed PD was found in 146 drivers (118 men, 28 women). The information of psychiatric morbidity was obtained from the Finnish Care Register for Health Care.

Results: The proportion of deceased drivers with PDs had increased significantly over the study period, particularly among females and those with PD NOS. Suicidality and use of medication affecting driving ability was more common among females with PD compared to males with PD. $88 \%$ of all deceased drivers with PD had comorbid psychiatric disorders.

Conclusion: Our findings indicate that PDs may predispose drivers to fatal motor vehicle accidents, particularly females. This study emphasize the importance of evaluating the fitness-to drive of subjects with PD and especially comorbid substance use disorders, which may relate to an increased risk of fatal motor accidents.

Keywords: Personality disorder, mortality, substance use disorders

\title{
Significant outcomes
}

- In Finland the proportion of deceased drivers with hospital-treated personality disorders (PD) has significantly increased during the years 1990 to 2011.

This article is protected by copyright. All rights reserved. 
- The increase was emphasized in female drivers with PD.

- Suicidality and medication use was more common among female drivers with PD.

\section{Limitations}

- Personality disorders are underestimated in register based data.

- This study lacks of alive control population with personality disorder.

\section{Introduction}

Personality disorders (PDs) are common, long-lasting behavioral patterns that significantly differ from social standards and expectations. The etiology of PDs is complex, having genetic and environmental factors $(1,2)$. Personality pattern is stable and of long duration, and its onset can be traced back to at least adolescence or early adulthood $(3,4)$. Symptoms of PD are often harmful and appear in many areas of life $(3,5)$. Clinically significant PDs manifest as disturbances in cognition, affects, impulse control and interpersonal relationships (6-8). The prevalence of PDs has been established as varying from $6 \%$ to $10 \%$ in population samples (8-11) to $24-60 \%$ in psychiatric patient samples (12-14). PDs are found to have psychiatric comorbidity (15) as well as an increased risk for suicide (16). Furthermore, PDs have been associated with low quality of life and high health care costs $(17,18)$. However, relatively little is known about fatal motor vehicle accidents (FMVA) involving drivers with PDs.

Previous studies have investigated self-reported personality traits and their relationship to driving behaviors and car accidents (19-23). Personality traits are closely related to driving behaviors in general (24). Personality traits are significantly correlated with both risky driving behavior and involvement in vehicle accidents. In particular, the traits of anger and normlessness are effective predictors for aggressive violations (25). A study among Chinese high-speed railway drivers found that personality traits, such as conscientiousness and agreeableness related to less frequent risky driving behavior (26). By using objective measures of driving behavior and a widely used personality

This article is protected by copyright. All rights reserved. 
construct, a causal pathway has been obtained through which personality and risky driving are associated with crashes and near-crashes rates in young drivers (27). In antisocial and borderline PDs, impulsive-aggressive behaviors and substance use disorders appear to be risk factors for young male deaths in motor vehicle accidents aged 26 years or over (28).Such symptoms, as impulsivity, difficulty controlling anger, reckless driving, has been associated with borderline PD (29).

In Finland the trend in death rates of drivers with psychiatric disorders has recently been increasing, particular from 2000 until 2007 for male, and during the 1990 until 2011 for female victims (30). Conversely, a decreasing trend in death rates has been observed for drivers without a history of psychiatric disorders. In a Finnish study, the prevalence of hospital treated PDs within the previous five years was $1.8 \%$ among drivers killed in road traffic accidents (30), although PDs were not analyzed among specific PD types.

\section{Aims of the study}

The aim of this study is to analyse the personality disorder (PD) diagnoses of drivers killed in fatal motor vehicle accidents (FMVA) in Finland during the years 1990-2011. The proportions of deceased drivers with PD of all driver deaths of FMVA were evaluated over the study period. Further, gender differences among drivers with PDs were examined in relation to lifetime comorbid psychiatric disorders and medico-legal findings (alcohol, medication influencing driving, illicit drugs) at the time of death.

\section{Material and methods}

\section{Study population}

The initial study population consisted of 4,930 drivers killed in FMVAs between the years1990-2011. Of this total, those excluded included foreign drivers ( $\mathrm{n}=98)$, those with inaccurate personal identify

This article is protected by copyright. All rights reserved. 
code and non-cases $(n=22)$, giving a final total of 4,810 drivers for our study. All deaths were investigated by Finnish road accident investigation teams (RAIT) (31). Since 2001, the operations of RAIT have been governed by legislation $(32,33)$. For the purpose of the current study, the RAIT data were linked with data from the national registers for health care and causes of death using the Finnish personal identity code of each study subject (34).

\section{Register-based data sources}

Accident information register: The database of road and cross-country traffic accidents is maintained by the Finnish Crash Data Institute (OTI ) previously known as the Finnish Motor Insurers' Centre (LVK) which provided the main data for our study (permission date 10/16/2013) (35). This database contains results from official investigations of fatal motor accidents conducted by twenty independent RAITs since 1968. This work of the RAITs has been statutory since 2001 ("Act on the investigation of road and cross-country traffic accidents No. 24/2001" (32), "Council of State decree on the investigation of road and cross-country traffic accidents No. 1512/2016”, 2016) (33). The OTI coordinates the work of the RAIT teams and administers the data collected by these teams. The ultimate purpose of the RAITs is to conduct comprehensive and method-based investigations of FMVAs (The Finnish Motor Insurers' Centre, 2004) (35). Each investigation team includes representatives from the police, the fields of medicine, vehicle technology, road maintenance and behavioural sciences, and other special branches. For further details see earlier piublications for the database used in this study (30) and the investigation method of FMVAs (35).

Care register for health care: Information on hospital treatments in either out- or inpatient settings was extracted from the National Care Register for Health Care (CRHC) provided by the Finnish National Institute for Health and Welfare (THL). The CRHC is a nationwide register covering comprehensively all treatment episodes in inpatient settings in all primary and specialized level care

This article is protected by copyright. All rights reserved. 
in Finland, including all mental and general hospitals, as well as the wards of local health centres, military wards, prison hospitals and private hospitals from the year 1969 onwards. In addition, the CRHC includes information on all treatments in out-patient settings for specialized health care level was available from the year1998 onwards. The CHRC data comprise treatment-based information, such as treatment diagnoses (main and co-morbid diagnoses), dates of admission and discharge and the length of hospital treatment. The register-based data from the CRHC enabled us to analyse the psychiatric morbidity of deceased drivers. Treatment diagnoses in the CRHC are defined according to the Finnish Classification of Diseases (36-38) is based on the International Classification of Diseases (ICD) (ICD-8 during 1969-1986, ICD-9 during 1987-1995) and from the year 1996 onwards to ICD10. THL has approved our access to the CRHC data for deceased drivers and provided the data for the current study (THL/1270/5.05.00/2013, 3/12/2014).

Cause of death register: Cause of death information was obtained from the official death certificates of drivers killed in FMVAs. All traffic deaths are examined by forensic medicine specialist physicians (“Act on the Inquest into the Cause of Death No. 459/1973”, 2011) (39). Official death certificates are completed after the examination and thenarchived by Statistics Finland, which provided the cause of death data for this study and approved their use (TK53-1422-13, 11/20/2013).

\section{Study subjects with personality disorder}

All diagnoses of PD (primary and additional diagnoses) (ICD-8 codes: 301.0-301.9, and ICD-9 codes: 300.1-300.9 and ICD-10 codes: F21, F 60-69) of deceased drivers were gathered from the CRHC and further reviewed by three psychiatrists. Preliminary evaluation of the presence of PD of the study subject was made by a junior investigator (TR). Senior investigators (PR and LK) confirmed the diagnoses to achieve a consensus on the PD diagnosis of each study subject. In addition to PD

This article is protected by copyright. All rights reserved. 
diagnosis, up to three of the most severe Axis I or Axis II psychiatric diagnoses of the study subjects were extracted from the CRHC and converted according to ICD -10 codes for the current study.

PDs were categorised into three clusters according the DSM-classification (3): Cluster A (includes paranoid, schizoid and schizotypal PDs), Cluster B (antisocial, borderline, histrionic and narcissistic PDs) and Cluster C (avoidant, dependent and obsessive-compulsive PDs). In addition, a category of personality disorder not otherwise specified (PD NOS) consist of those study subjects having features of more than one specific PD that did not meet the full criteria of any specific PD, yet caused significant impairment in social or occupational functioning or subjective distress A passiveaggressive PD (ICD-code F 60.8) was excluded from the main body of the latest version of the DSMIV-TR, but the diagnosis PD NOS may be used instead. Subjects with a narcissistic PD diagnosed according to ICD 8 and ICD 9 classification in Cluster B, and according to ICD 10 in PD NOS. PD diagnosis was found in 158 study subjects. Subjects with concurrent schizophrenia $(n=5)$ or schizoaffective disorder diagnosis $(n=6)$ and factitious disorder $(n=1)$ were excluded. Figure 1 (flowchart) shows the selection procedure for the study subjects with PD.

\section{Covariates}

Socio-demographics: Socio-demographic characteristics, based on the RAIT data, included age (in years) at the time of the accident, marital status (unmarried, married /cohabiting, divorced, other/unknown), education (basic, intermediate, high, other/unknown) and employment status (at work, student, pensioner, unemployed, and other/unknown) at the time of death.

Medico-legal findings: Information on the presence of alcohol, medication affecting driving ability, and illicit drugs at the time of accident was based on the medico-legal examination of the deceased drivers. Alcohol use at the time of death was based on the measured blood alcohol concentration $(\mathrm{BAC}, \%$ ) and was categorised as follows: no alcohol or BAC $<0.5 \%$, driving under the influence of

This article is protected by copyright. All rights reserved. 
alcohol (DUI) (BAC between 0.5-1.19\%), aggravated DUI (BAC >1.2\%o). The use of illicit drugs and medication able to impair driving ability were available from the data as dichotomized variables (yes/no).

Comorbid psychiatric disorders: Based on the information from the $\mathrm{CRCH}$, the co-morbid psychiatric diagnoses, included for up to three of the most severe Axis I psychiatric diagnoses, were categorized according to major diagnostic groups: F10-F19 (substance use related disorder), F20-F29 (psychotic disorder), F30-F39 (affective disorder), F40-F49 (anxiety disorder).

Factors relating to driving event: The information from the RAIT data on the role of driver in the accident included the following categories: being at fault for the collision, single vehicle collision and other (not at fault driver, and collision with an animal). The passengers in the car (information available from the year 2002 onwards) were categorised as follows: no passengers, family member(s), and other persons. The main purpose of driving covers categories for work related driving, running errands, leisure drive to a planned destination, leisure drive without a planned destination, and other purpose. Driver's suicidal intention (yes / no) was based on RAITs police member's evaluation during their FMVA investigation.

\section{Statistical analysis}

The statistical significance of group differences in categorical variables was assessed using the Pearson's Chi-square test or Fisher's Exact test, and in continuous variables with the Student's t-test or Mann-Whitney U-test. These analyses were performed with IBM Spss Statistics 23 software. For the time trend analysis, a Joinpoint regression program and the Annual Percent Change (APC) method

This article is protected by copyright. All rights reserved. 
were employed (40). Owing to the relatively small number of PD cases, three-year moving averages were used in statistical modelling.

\section{Results}

The final study sample consisted of 146 deceased drivers, 118 (80.8\%) male and 28 (19.2\%) female, with any diagnosis of PD, accounting $3.1 \%$ of all drivers killed in fatal motor vehicle accidents in Finland between 1990 and 2011. Eighteen (12.2\%) of the subjects (12, 10.2\% males and 6, 21.4\% females) had multiple PD diagnoses, which were categorized according to the primary PD diagnosis. Eleven subjects had diagnoses of borderline and other PD (10 histrionic PD, 1 avoidant PD) and they were diagnosed in Cluster B (all borderline PD). Seven subjects had diagnoses of antisocial and other PD (6 borderline PD and 1 borderline and narcissistic PD) and they were diagnosed in Cluster B (all antisocial PD).

Among deceased drivers with PD, 10 (6.9\%) subjects fulfilled the criteria of cluster A PD, 63 (43.2\%) of cluster B PD and 8 (5.5\%) of cluster C PD, while 65 (44.5\%) had diagnosis for PD NOS. Borderline PD ( $n=41,28.1 \%$ of all PDs) and antisocial PD ( $n=18,12.3 \%$ of all PDs) were the most common specific types of PDs in deceased drivers.

\section{Socio-demographic characteristics of study subjects}

The socio-demographic characteristics of the deceased drivers with PD by gender are shown in Table 1. The mean age (SD) at the time of death did not statistically significantly differ between genders being $37.2(11.7)$ years in men and $40.2(14.0)$ years in women $(\mathrm{P}=0.237)$. One half of male victims were unmarried compared to one quarter of females $(\mathrm{P}=0.021)$. The females were more often highly educated $(\mathrm{p}=0.007)$ whereas male victims more often had a basic level of education $(\mathrm{P}=0.045)$.

This article is protected by copyright. All rights reserved. 


\section{Driving event related factors}

As seen in Table 2, a total of $98 \%$ of male and $92 \%$ of female drivers with PD were defined as being at-fault driver of head-on and single-vehicle collision. In drivers with PD, a female preponderance was found in head-on collisions ( $\mathrm{p}=0.0001)$ and male excess in single-vehicle collisions $(\mathrm{p}<0.001)$. The great majority of female (80\%) and male drivers (77\%) with PD were driving alone without passengers at the time of their accident. $46 \%$ of females and $18 \%$ of males with PD were thought to have suicidal intent in their motor vehicle accidents $(\mathrm{p}<0.001)$.

\section{Lifetime psychiatric comorbidity and medico-legal findings}

Table 3 shows Axis I psychiatric comorbidity and medico-legal findings of deceased drivers. Female drivers with PD more commonly had comorbid affective disorder compared with males with PD (71\% vs. $40 \%, \mathrm{P}=0.003)$. Co-morbid substance use disorder was more common in males compared to females, the gender-difference being of marginally significant ( $57 \%$ vs. $39 \%, \mathrm{P}=0.095)$. A nearly equal proportion of male (57\%) and female drivers with PD (50\%) had been under the influence of alcohol at the time of their accident. Further, $43 \%$ of men and $32 \%$ of women exceeded the limit of aggravated DUI (BAC $\geq 0.5 \%$ ). A significantly higher proportion of female drivers with PD (68\%) compared to male males $(41 \%)$ had used medication with the potential to influence their driving ability ( $\mathrm{p}=0.009)$. Moreover, $12 \%$ of the men but none of the women with PD had used illicit drugs during the time leading up of their accident.

\section{Proportion of deceased drivers with personality disorder}

Figure 2 presents the time trends in proportions (\%) of deceased drivers with PDs of all drivers killed in fatal motor vehicle collisions during the 22-year follow-up period. As Figure 2a shows, the proportion of deceased drivers with PD has statistically significantly increased in the total data

This article is protected by copyright. All rights reserved. 
(Annual Percentage Change, APC $=4.32,95 \% \mathrm{CI} 1.6-7.12, \mathrm{p}=0.003)$, in men $(\mathrm{APC}=3.25,95 \% \mathrm{CI}$ $0.49-6.08, \mathrm{p}=0.023)$ and in women $(\mathrm{APC}=9.46,95 \% \mathrm{CI} 6.56-12.44, \mathrm{p}<0.001)$. The time trends differed significantly between male and female drivers with PD (test for parallelism, $\mathrm{p}<0.001$ ).

As visualized in Figure 2b, the increase in the proportion of deceased drivers with PD was significant in drivers with PD NOS $(\mathrm{APC}=6.36,95 \% \mathrm{CI} 2.76-10.85, \mathrm{p}=0.001)$. An increasing time trend, although not reaching the limit for statistical significance, was also found in drivers with Cluster B PDs ( $\mathrm{APC}=3.23,95 \% \mathrm{CI}-0.47-7.07, \mathrm{p}=0.084)$ and among those with Cluster A and C PDs $(\mathrm{APC}=1.99,95 \% \mathrm{CI}-0.78-4.82, \mathrm{p}=0.151)$. There was a significant difference in trends between drivers with Cluster B PDs and PD NOS (test for parallelism, $\mathrm{p}=0.002$ ), but not between drivers with PD NOS or Cluster A and C PDs ( $\mathrm{p}=0.066)$ and those with Cluster B or Cluster A and C PDs $(\mathrm{p}=0.529)$.

\section{Discussion}

The major finding of our study was that the proportion of drivers with PDs killed in fatal motor vehicle accidents has increased during the last two decades by up to two-fold. The increase was particularly apparent in female drivers with PD and those suffering from PD NOS. Our finding is in contrast to the decline in rates of traffic accidents observed in Finland from 1993 onwards (41), and in Europe generally (42).

The prevalence of PDs in the general population has remained relatively stable, at between 6-10\% over the last twenty years (8-10). Our results, showing an increase in deaths of drivers with PD, may be partly explained by the fact that that the likelihood of receiving a diagnosis of PD may have increased since the 1990s. Structured clinical assessments of PDs have been developed in recent decades, which have been reported to have increased the frequency of PD diagnoses (43). The use of diagnostic interviews, e.g. SCID -II (Structured Clinical Interview for DSM-IV Personality

This article is protected by copyright. All rights reserved. 
Disorders) (44) has become more commonplace in clinical practice in Finland since the 1990s, improving the diagnostics of PDs. Further, the number of Finnish road traffic deaths involving drivers with psychiatric disorders has shown an increasing trend (31) while, the annual number of fatal motor vehicle accidents in Finland has been reported a decrease (36). However, the improved diagnostics of PDs may not explain totally an increase in deceased of drivers suffering from PD. A recent large systematic review article of the evidence for fitness-to-drive among people with the mental health conditions, including PDs, (45). Our study is an important addition to the previous literature focusing on the role of PD in motor vehicle accidents and, particularly, in deaths of drivers with PD because published studies of those topic are mainly lacking.

Of all PDs observed in our study population, the most prominent increase in proportion of deceased drivers was seen among those diagnosed with PD NOS, followed by drivers with Cluster B PDs. Symptoms of Cluster B PDs, such as irresponsibility, impulsivity or recklessness $(3,28)$ may associated with risk for traffic accidents. The interaction between cluster B PD and age over 26 years had been shown to be significant predictor of car fatalities (28). In clinical practice, subjects who met the criteria for severe personality characteristics, but who do not fulfil the criteria for specific type of PD, can obtain a diagnosis of PD NOS. Accordingly, PD NOS is found to be as valid as any other PD by DSM-criteria (46). In a Danish study (47) showed that the use of PD NOS diagnoses has been found to increase among hospital treated in and outpatients. Our findings suggest that subjects with PD NOS may have personality features which impair important areas in driving functioning.

The increasing time trend in vehicle accident deaths was particularly highlighted in female drivers with PD. This notable gender difference is an interesting finding because, in previous studies, male drivers have been found to have more traffic accidents than females (48). Further, male drivers were found to be more angry and aggressive drivers than female drivers in a telephone survey study among young and adult drivers (49). In our study, the observed gender difference in death rates of drivers with PD may also be explained by fact that half of the deceased female drivers were diagnosed hospital treated borderline PD. In a previous Finnish study (50) among a population based sample, using SCID-II-interview, a statistically significant gender difference was only observed in the case of

This article is protected by copyright. All rights reserved. 
antisocial PD, which was more common among males than females. Our findings indicate that PDs may predispose drivers to fatal motor vehicle accidents, particularly in females. Dumais et al. (28) found that cluster B PDs, borderline and antisocial PDs increased the risk of dying in motor vehicle accidents over three-fold in young men. However, not all subjects with PDs are treated in psychiatric hospitals. This applies especially for individuals with antisocial PD, in which the majority are male (51). Many of them may have been in prison (52) or treated in outpatient addiction clinics. Therefore, it is likely that our study underestimates the prevalence of antisocial PD in drivers involved in fatal traffic accidents. In addition, hospital admissions account for a limited number of subjects with cluster C PDs (50), which may affect our findings. To better understand the further risks of driving in traffic and vulnerability to accidents, it would be useful to study further impulse control among subjects with any PD, as well among females as males.

Vehicle accidents thought to be due to suicidal intention were more common among females than males with PD in this study. According to police evaluations, nearly one half of women compared to one fifth of men with PD involved in fatal motor vehicle accidents were thought to have suicidal intent. A previous study (54) has established that driver suicides represent a small proportion (2\%) of all suicides committed in Finland each year. However, according to their findings, the proportion of driver suicides of all fatal motor vehicle accidents is greater (8-9\%). A previous study using the same database as the current study (Sassi et al.54) found a significantly increasing time trend in fatal accidents due to suicides in light motor vehicle collisions with heavy vehicles.

According to medico legal findings, nearly half of deceased drivers with PD had used medication which could have affected their driving ability, being emphasised in female drivers with PD. Therefore, the role of other intoxicants in the fatal motor vehicle accident cannot be excluded. Further, the percentage of drivers with illegal blood alcohol concentrations (57\% men, 50\% women) was higher among subjects with PD than in other fatal car accidents (24 \%) in Finland during years 2012-2016 (55). Our finding is in line with a study by Dumais et al. (28). They found that both cluster B PDs and substance use disorders increased the risk of dying in fatal motor vehicle accidents approximately to four-fold. Comorbidity with substance use disorders and cluster B PDs are common.

This article is protected by copyright. All rights reserved. 
Up to $80 \%$ of subjects with borderline PD have been reported as having a co-morbid diagnosis of substance use disorder at lifetime (56-58). The most consistent correlates of risky driving patterns are shown to be antisocial behaviour, antisocial peers, and binge drinking (58). In our study, regardless of the gender nearly ninety percent of deceased drivers with PD had comorbid psychiatric disorder. Affective disorder was characteristics of female drivers with PD. Depression or anxiety are reported to increase the likelihood for road accidents by over two-fold among professional male drivers (59). Risky driving is seen as a multidimensional phenomenon, constituting substance use, psychiatric disorders and reckless driving (60). Co-morbid psychiatric disorders may also associate with fatal motor vehicle accidents among decreased drivers with PD in both genders.

The present study has several limitations, which should be considered when interpreting the results. Firstly, diagnosing PD is often problematic. In clinical practice PD diagnoses are made with caution and, therefore, their prevalence is often underestimated (61). Secondly, the diagnostics of PDs has improved since the 1990s (43). It is clear that PDs are diagnosed more frequently in the 2000's than previously. Thirdly, there is a risk of selection bias in a study sample. Subjects with borderline PD are found to seek treatment far more often than subjects with other types of PD $(62,63)$ and therefore they might be much more likely to appear in a register than, for instance, subjects with cluster A or C PD (50). Further, comorbid Axis I psychiatric disorders can diminish the diagnostic process of PDs $(64,65)$. Our initial study population covers all deceased drivers in Finland over the 22-year study study period from 1990 to 2011. Unfortunately, we had no access to, or permissions to use register-based data on living patients or healthy persons. Therefore, we are not able to perform comparisons of our data control samples extracted from the health care registers. Furthermore, we were unable to evaluate the impact of changes in automobile safety on our results. The safety of cars and traffic safety in general has improved during the past twenty years, reducing the risk of death in traffic accidents (66).

The strengths of our study include the use of data from three national registers, which were reliably combined using personal identification codes. The main data comes from the database of road and cross-country traffic accidents, which is a comprehensive, national source of statutory data

This article is protected by copyright. All rights reserved. 
gathered by RAIT teams (33). In this study we used data of FMVA covering two decades. The validity of the CRHC and cause of death data register also provided high-quality data for scientific purposes (67-69).

We conclude that the proportion of fatal motor vehicle accidents among persons with PDs have markedly increased in Finland between the years 1990 and 2011. In particular, driving under the influence of alcohol was common among subjects with PD. Medication use at the time of accident and the presence of suicidal intention behind the fatal motor vehicle accident was apparent in female drivers with PD. This study emphasize the importance of evaluating the fitness-to drive of subjects with PD and, particularly, in those having problematic alcohol and drug use, which may relate to an increased risk of fatal motor accidents. Further population based studies among drivers with PD are needed.

This article is protected by copyright. All rights reserved. 


\section{References}

1. Tredget JE, The aetiology, presentation and treatment of personality disorders. J Psychiatr Ment Health Nurs 2001;8:347-356.

2. Coid J. Epidemiology, public health and the problem of personality disorder. Br J Psychiatry 2003;182;S3-10.

3. American Psychiatric Association, Diagnostic and Statistical Manual of Mental Disorders. Text revision (DSM-IV-TR), fourth ed., American Psychiatric Association, Washington, DC, 2000.

4. Bernstein DP, Cohen P, Skodol A, Bezirganian S, Brook J.S. Childhood antecedents of adolescent personality disorders. Am J Psychiatry 1996;153:907-13.5.

5. World Health Organization, The ICD-10 Classification of Mental and Behavioral Disorders: Diagnostic Criteria for Research, World Health Organization, Geneva, 1993.

6. Crawford TN, Cohen P, Johnson JG, et al. Self-Reported Personality Disorder in the Children in the Community Sample: Convergent and Prospective Validity in Late Adolescence and Adulthood. J Pers Dis 2005;19:30-52.

7. De Clercq B, De Fruyt F. Childhood antecedents of personality disorder. Curr Opin Psychiatry 2007;20:57-61.

8. Samuels J. Personality disorders: epidemiology and public health issues. Int Rev Psychiatry 2011;23:223-233.

9. Samuels J. Prevalence and correlates of personality disorders in a community sample. Br J Psychiatry 2002;180:536-542.

10. Torgersen S, Kringlen E, Cramer V. The Prevalence of Personality Disorders in a Community Sample. Arch Gen Psychiatry 2001;58:590-596.

11. Gawda B, Czubak K. Prevalence of personality disorders in a general population among men and women. Psychol Rep 2017;120:503-519.

12. Zimmerman M, Chelminski I, Young D. The Frequency of Personality Disorders in Psychiatric Patients. Psychiatr Clin North Am 2008;31:405-420.

13. Grilo CM, McGlashan TH, Skodol AE. Stability and course of personality disorders: the need to consider comorbidites and continuities between axis I psychiatric disorders and axis II personality disorders. Psychiatr Q 2000;71:291-307.

14. Marinangeli MG, Butti G, Scinto A, et al. Valutazione della prevalenza di disturbi di personalità in una popolazione di pazienti psichiatrici ospedalizzati per disturbi dell'umore, disturbi da uso di sostanze psicoattive e disturbi d'ansia. Epidemiol Psichiatr Soc 2000;9:36-44.

15. Lenzenweger MF, Lane MC, Loranger AW, Kessler RC. DSM-IV personality disorders in the National Comorbidity Survey Replication. Biol Psychiatry 2007;62:553-564.

16. Björkenstam E, Björkenstam C, Holm H, Gerdin B, Ekselius L. Excess cause-specific mortality in in-patient-treated individuals with personality disorder: 25 -year nationwide population-based study. Br J Psychiatry 2015;207:339-345.

This article is protected by copyright. All rights reserved. 
17. Feenstra DJ, Hutsebaut J, Laurenssen E MP, et al. The burden of disease among adolescents with personality pathology: quality of life and costs. J Personal Disorder 2012;26:593-604.

18. Magallón-Neri EM, Canalda GC, De la Fuente JE, et al. The influence of personality disorders on the use of mental health services in adolescents with psychiatric disorders. Compr Psychiatry 2012;53:509-15.

19. Yang J, Du F, Qu W, et al. Effects of Personality on Risky Driving Behavior and Accident Involvement for Chinese Drivers. Traffic Inj Prev 2013;14:565-571.

20. Arthur W, Doverspike D. Predicting motor vehicle crash involvement from a personality measure and driving knowledge test. J Prev Interv Community 2001;22:35-42.

21. Gulliver P, Begg D. Personality factors as predictors of persistent risky driving behavior and crash involvement among young adults. Inj Prev 2007;13:376-381.

22. Nichols AL, Classen S McPeek R, Breiner J. Does personality predict driving performance in middle and older age? An evidence-based literature review. Traffic Inj Prev 2012;13:133-143.

23. Machin MA, Sankey KS. Relationships between young drivers' personality characteristics, risk perceptions, and driving behavior. Accid Anal Prev 2008;40:541-547.

24. Clarke, S, Robertson, I.T. A Meta-Analytic Review of the Big Five Personality Factors and Accident Involvement in Occupational and Non-Occupational Settings. Journal of Occupational and Organizational Psychology 2005;78:355-376.

25. Garrity R, Demick J. Relations among personality traits, mood states, and driving behaviors. Journal of Adult Development 2001;8:109-118.

26. Guo M, Wei W, Liao G, Chu F. The impact of personality on driving safety among Chinese highspeed railway drivers. Accid Anal Prev 2016;92:9-14.

27. Ehsani J, Li K, Simons-Morton B, et al. Conscientious personality and young drivers' crash risk. J Safety Res 2015;54:83-87.

28. Dumains A, Lesage AD, Boyer R, et al. Psychiatric risk factors for motor vehicle fatalities in young men. Can J Psychiatr 2005;50:838-844.

29. Sansone RA, Sansone LA. Road rage: What's driving it? Psychiatry 2010;7:14-18.

30. Kujansuu A, Rautiainen S, Hakko H, et al. Drivers' psychiatric disorders and fatal motor vehicle accidents in Finland. J Psychiatr Res 2017;84:227-236.

31. http://www.oti.fi/fi/onnettomuustietoinstituutti/liikenneonnettomuuksien-tutkinta

32. Act on the investigation of road and cross-country traffic accidents No. 24/2001, 2001. http://www.finlex.fi/fi/laki/alkup/2001/20010024 (accessed 7.20.15)

33. Council of State degree on the Investigation of road and cross-country traffic accidents No. 1512/2016, 2001. http://www.finlex.fi/fi/laki/alkup/2016/20161512

34. Population Register Centre, 2016. Personal identify code, 2016. http://www.vrk.fi/default.aspx?id=45 (accessed 7.17.15)

35. The Finnish Motor Insurers' Centre, 2015. Road Safety. http//www.lvk.fi/en/traffic-safety (accessed 1.1.15)

This article is protected by copyright. All rights reserved. 
36. Tautiluokitus, 1969. Lääkintöhallitus.

37. Tautiluokitus, 1987. Lääkintöhallitus.

38. Tautiluokitus ICD-10, 1995. Sosiaali- ja terveysalan tutkimus- ja kehittämiskeskus.

39. Act on the Inquest Into the Cause of Death No. 459/1973, 2011. https://www.finlex.fi/fi/laki ajantasa/1973/19730459 (accessed 1.1.15)

40. Kim HJ, Fay MP, Feuer EJ, Midthune DN. Permutation tests for joinpoint regression with applications to cancer rates. Stat Med 2000;19:335-351.

41. Liikennevakuutuskeskus, 2014. Raportti liikennevahinkojen tutkijalautakuntien tutkimista moottoriajoneuvossa kuolleiden onnettomuuksista vuonna 2013 [VALT Annual Report 2013. Fatal Accidents Investigated by Finnish Road Accident Investigation teams.] Liikennevakuutuskeskus. Vakuutusyhtiöiden liikenneturvallisuustoimikunta (VALT), Helsinki.

42. European Comission, Road safety.2015. Statistics-accident data http://ec.europa.eu/transport/road_safety/specialists/statistics/index_en.htm (accessed 1.1.15).

43. Zimmermann M, Mattia JI. Differences between clinical and research practices in diagnosing borderline personality disorder. Am J Psychiatry 1999;156:1570-1571.

44. First MB, Spitzer RL, Gibbon M, Williams JBW. User's guide for the Structured Clinical interview for DSM-IV Axis II personality disorders. Washington DC; American psychiatric Press. 1997.

45. Unsworth CA, Baker AM, So MH, et al. A systemic review of evidence for fitness-to-drive among people with the mental health conditions of schizophrenia, stress/anxiety disorder, depression, personality disorder and obsessive compulsive disorder. BMC Psychiatry 2017;17:318.

46. Coccaro EF, Nayyer H, McCloskey MS. Personality disorder-not otherwise specified evidence of validity and consideration for DSM-5. Compr Psychiatry 2012;53:907-914.

47. Pedersen L, Simonsen E, Incidence and prevalence rates of personality disorders in Denmark - a register study. Nord J Psychiatry 2014;68:543-548.

48. González-Iglesias B, Gómez-Fraguela JA Ángeles Luengo-Martín MA. Driving anger and traffic violations: Gender differences. Transportation Research Part F 15, 2012;404-412.

49. Rhodes N, Pivik K. Age and gender differences in risky driving: The roles of positive affect and risk perception. Accid Anal Prev 2011;43:923-931.

50. Kantojärvi L, Veijola J, Läksy K, et al. Comparison of hospital-treated personality disorders and personality disorders in a general population sample. Nord J Psychiatry 2004; 58:357-362.

51. Sher L, Siever LJ, Goodmana M, et al. Gender differences in the clinical characteristics and psychiatric comorbidity in patients with antisocial personality disorder. Psychiatry Res 2015;229:685689.

52. Coid J, Ullrich S. Antisocial personality disorder is on a continuum with psychopathy. Comprehensive Psychiatry 2010;51:426-433.

53. Hernetkoski KM, Keskinen EO, Parkkari IK. Driver suicides in Finland--are they different in northern and southern Finland? Int J Circumpolar Health. 2009;68:249-60.

This article is protected by copyright. All rights reserved. 
54.Sassi S, Hakko H, Räty E, Riipinen P. Light motor vehicle collisions with heavy vehicles Psychosocial and health related risk factors of drivers being at-fault for collisions. Forensic Sci Int. 2018:291:245-252.

55. Intoxicated Drivers in Fatal Road Accidents 2012-2016 - Statistical review. OTI 2017.

56. Hidalgo-Mazzei D, Walsh E, Rosenstein L, Zimmerman M. Comorbid bipolar disorder and borderline personality disorder and substance use disorder. J Nerv Ment Dis. 2015;203:54-57.

57. Trull TJ, Freeman LK, Vebares TJ, et al. Borderline personality disorder and substance use disorders: an updated review. Borderline Personal Disord Emot Dysregul 2018;5:15.

58. Vassalo S, Lahausse J, Edwards B. Factors affecting stability and change in risky driving from late adolescence to the late twenties. Accid Anal Prev 2016;88:77-87.

59. Alavi SS, Mohammadi MR, Souri H, et al. Personality, Driving Behavior and Mental Disorders Factors as Predictors of Road Traffic Accidents Base on Logistic Regression. Iran J Med Sci, 2017;42:24-31.

60. McDonald CC, Sommers MS, Fargo JD. Risky Driving, Mental Health, and HealthCompromising Behaviors: Risk Clustering in Late Adolescents and Adults. Inj Prev. 2014;20:365-72.

61. Bender DS, Dolan RT, Skodol AE, et al. Treatment utilization by patients with personality disorders. Am J Psychiatry 2001;158:295-302.

62. Bender, D S, Skodol, AE, Pagano, ME. et. al. Prospective assessment of treatment use by patients with personality disorders. Psychiatric Services 2006: 57;254-257.

63. Coid J, Yang M, Bebbington P, et al. Borderline personality disorder: health service use and social functioning among a national household population. Psychol Med. 2009;39:172131 .

64. Ekselius L Personality disorder: a disease in disguise. Ups J Med Sci. 2018 Dec;123: 194-204.

65. Tillfors M, Ekselius L. Social phobia and avoidant personality disorder: are they separate diagnostic entities or do they reflect a spectrum of social anxiety? Isr J Psychiatry Relat Sci. 2009; 46:25-33.

66. Räty, E, Kari, T. Henkilöautojen kolariturvallisuuden kehitys 2017 https://www.lvk.fi/automallitutkimus.

67. Miettunen J, Suvisaari J, Haukka J, Isohanni M. Use of register data for psychiatric epidemiology in the Nordic countries. Textbook of Psychiatric Epidemiology, John Wiley \&Sons, Ltd, Chichester, UK 2011, pp 117-131.

68. Sund R. Quality of the Finnish hospital discharge register: a systemic review. Scand J Public Health 2012;40:505-515.

69. Lahti R, Penttilä A. The validity of death certificates: routine validation of death certification and its effects on mortality statistics. Forensic Sci Int 2001;115:15-32.

This article is protected by copyright. All rights reserved. 
Table 1. The socio-demographic characteristics of male and female drivers with personality disorder killed in fatal motor vehicle accidents in Finland 1990-2011, by gender.

\begin{tabular}{llllllll}
\hline Socio-demographics & $\begin{array}{l}\text { Total } \\
(\mathbf{n = 1 4 6})\end{array}$ & \multicolumn{2}{l}{$\begin{array}{l}\text { Male } \\
(\mathbf{n = 1 1 8})\end{array}$} & $\begin{array}{l}\text { Female } \\
(\mathbf{n = 2 8})\end{array}$ & P-value \\
& $\mathbf{n}$ & $\mathbf{\%}$ & $\mathbf{n}$ & $\mathbf{n}$ & $\mathbf{\%}$ & \\
& & & & & & & \\
\hline Age & 21 & 14 & 17 & 14 & 4 & 14 & 1.000 \\
$18-24$ & 27 & 19 & 24 & 20 & 3 & 11 & 0.238 \\
$25-29$ & 40 & 27 & 34 & 29 & 6 & 21 & 0.431 \\
$30-39$ & 37 & 25 & 27 & 23 & 10 & 36 & 0.160 \\
$40-49$ & 14 & 10 & 11 & 9 & 3 & 11 & 0.732 \\
$50-59$ & 7 & 5 & 5 & 4 & 2 & 7 & 0.619 \\
60 and over & & & & & & &
\end{tabular}

\section{Marital status}

$\begin{array}{llllllll}\text { Married / } & 36 & 25 & 27 & 23 & 9 & 32 & 0.307 \\ \text { Cohabiting } & 65 & 45 & 58 & 49 & 7 & 25 & 0.021 \\ \text { Unmarried } & 27 & 19 & 20 & 17 & 7 & 25 & 0.324 \\ \text { Divorced } & 18 & 12 & 13 & 11 & 5 & 18 & 0.324\end{array}$

\section{Education}

$\begin{array}{llllllll}\text { High } & 11 & 8 & 5 & 4 & 6 & 21 & 0.007 \\ \text { Intermediate } & 39 & 27 & 31 & 26 & 8 & 29 & 0.805 \\ \text { Basic } & 61 & 42 & 54 & 46 & 7 & 25 & 0.045 \\ \text { Other / unknown } & 35 & 24 & 28 & 24 & 7 & 25 & 1.000\end{array}$

\section{Employment status}

\begin{tabular}{|c|c|c|c|c|c|c|c|}
\hline At work & 64 & 44 & 50 & 42 & 14 & 50 & 0.465 \\
\hline Student & 15 & 10 & 10 & 9 & 5 & 18 & 0.166 \\
\hline Pensioner & 23 & 16 & 21 & 18 & 2 & 7 & 0.249 \\
\hline Unemployed & 19 & 13 & 17 & 14 & 2 & 7 & 0.531 \\
\hline Other /unknown & 25 & 17 & 20 & 17 & 5 & 18 & 1.000 \\
\hline
\end{tabular}

This article is protected by copyright. All rights reserved. 
Table 2. Driving event -related factors of drivers with personality disorder killed in fatal motor vehicle accidents in Finland during 1990-2011, by gender.

\begin{tabular}{|c|c|c|c|c|c|c|c|}
\hline & \multirow[t]{2}{*}{$\begin{array}{l}\text { Total } \\
(n=146)\end{array}$} & \multicolumn{2}{|l|}{$\begin{array}{l}\text { Male } \\
(n=118)\end{array}$} & $\begin{array}{l}\text { Female } \\
(n=28)\end{array}$ & \multicolumn{2}{|c|}{ P-value } & \\
\hline & & $\%$ & $\mathbf{n}$ & $\%$ & $\mathbf{n}$ & $\%$ & \\
\hline \multicolumn{8}{|l|}{ Driver being at-fault for collision } \\
\hline Yes, head-on collision & 65 & 45 & 45 & 38 & 20 & 71 & 0.001 \\
\hline Single-vehicle collision & 77 & 53 & 71 & 60 & 6 & 21 & $<0.001$ \\
\hline Not at-fault driver/collision to an animal & 4 & 2 & 2 & 2 & 2 & 7 & 0.166 \\
\hline \multicolumn{8}{|l|}{ Passengers ${ }^{\dagger}$} \\
\hline No passengers & 67 & 46 & 51 & 77 & 16 & 80 & 1.000 \\
\hline Family member(s) & 5 & 3 & 2 & 3 & 3 & 15 & 0.080 \\
\hline Other person(s) & 14 & 10 & 13 & 20 & 1 & 5 & 0.172 \\
\hline \multicolumn{8}{|l|}{ Purpose of driving } \\
\hline Work related driving & 7 & 5 & 7 & 6 & 0 & 0 & 0.347 \\
\hline Running errands & 20 & 14 & 15 & 13 & 5 & 18 & 0.541 \\
\hline Leisure drive to a planned destination & 36 & 25 & 30 & 25 & 5 & 18 & 0.469 \\
\hline
\end{tabular}

This article is protected by copyright. All rights reserved. 
Leisure drive without a planned destination

Other purpose

Not known

Drivers suicidality ${ }^{\ddagger}$, (yes / no)

$\dagger$ Information collected from the year 2002 onwards

$\ddagger$ Police member of the RAIT evaluated that suicidal intention may associate the accident

This article is protected by copyright. All rights reserved. 
Table 3. Lifetime comorbid psychiatric disorders and medico-legal findings at the time of accident of drivers with personality disorder killed in fatal motor vehicle accidents in Finland during 1990-2011, by gender.

\begin{tabular}{|c|c|c|c|c|c|c|c|}
\hline & \multicolumn{2}{|c|}{$\begin{array}{l}\text { Total } \\
(n=146)\end{array}$} & \multicolumn{2}{|c|}{$\begin{array}{l}\text { Male } \\
(n=118)\end{array}$} & \multicolumn{2}{|c|}{$\begin{array}{l}\text { Female } \\
(n=28)\end{array}$} & \multirow[t]{2}{*}{ P-value } \\
\hline & $\mathbf{n}$ & $\%$ & $\mathbf{n}$ & $\%$ & $\mathbf{n}$ & $\%$ & \\
\hline \multicolumn{8}{|l|}{ Lifetime psychiatric comorbidity } \\
\hline Any psychiatric disorder & 128 & 88 & 102 & 86 & 26 & 93 & 0.527 \\
\hline Substance use disorder & 73 & 50 & 62 & 57 & 11 & 39 & 0.095 \\
\hline Anxiety disorder & 35 & 24 & 26 & 22 & 9 & 32 & 0.260 \\
\hline Affective disorder & 67 & 46 & 47 & 40 & 20 & 71 & 0.003 \\
\hline Psychotic disorder & 14 & 9 & 11 & 9 & 3 & 11 & 0.732 \\
\hline Comorbid personality disorder & 18 & 12 & 12 & 10 & 6 & 21 & 0.116 \\
\hline \multicolumn{8}{|l|}{ Medico-legal findings } \\
\hline Alcohol (BAC,\%o) & 65 & 45 & 51 & 43 & 14 & 50 & 0.401 \\
\hline $\mathrm{No} /<0.5$ & 21 & 14 & 16 & 14 & 5 & 18 & 0.565 \\
\hline $\mathrm{DUI}^{\dagger}(0.5-1.19)$ & 60 & 41 & 51 & 43 & 9 & 32 & 0.264 \\
\hline \multicolumn{8}{|l|}{ Aggravated DUI $^{\dagger}(>1.2)$} \\
\hline Medication influencing driving & 67 & 46 & 48 & 41 & 19 & 68 & 0.009 \\
\hline Illicit drugs & 14 & 9 & 14 & 12 & 0 & 0 & 0.072 \\
\hline
\end{tabular}

$\S \mathrm{DUI}=$ driving under influence of alcohol

This article is protected by copyright. All rights reserved. 


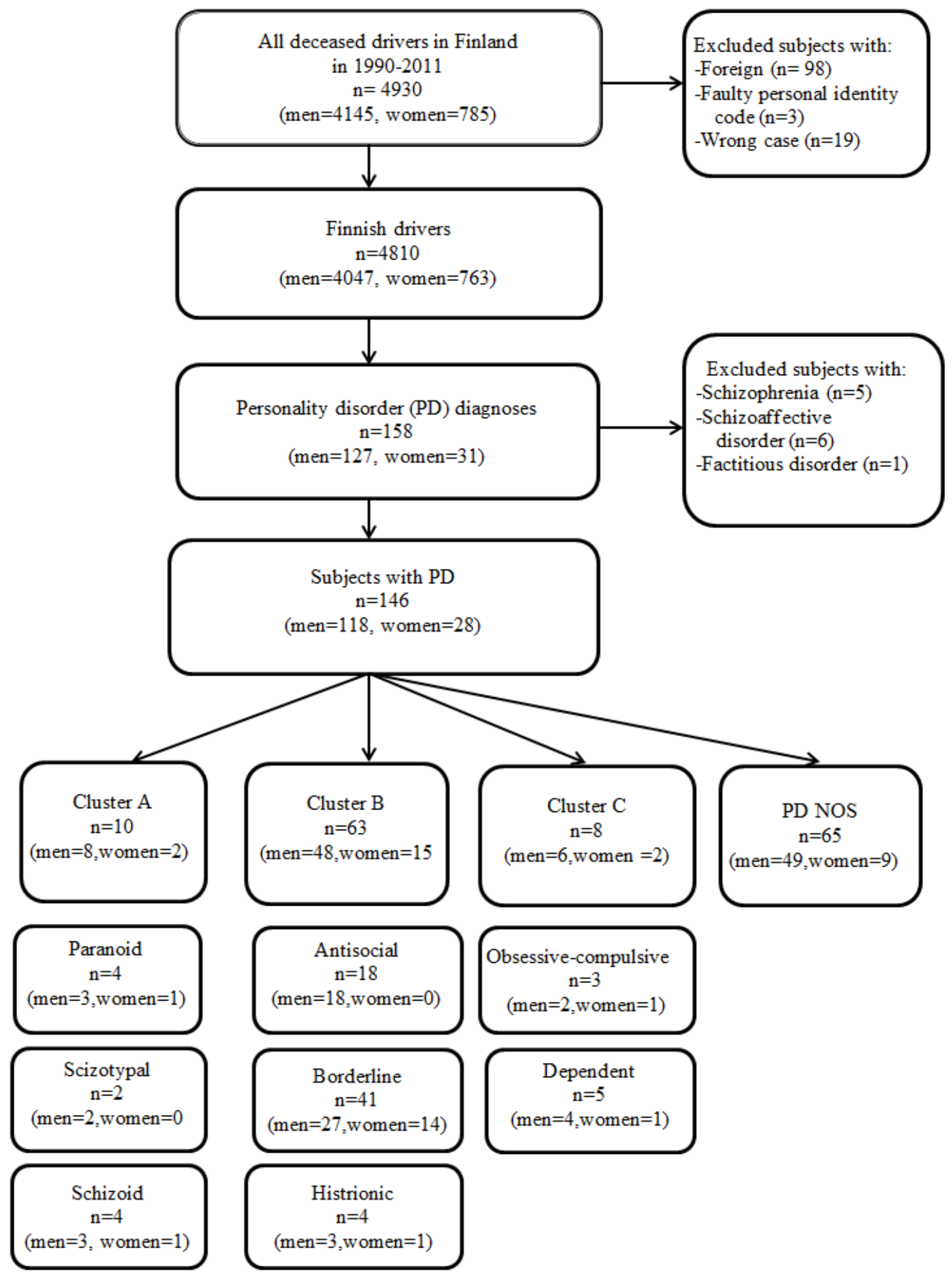

Figure 1. The flowchart of the personality disorders assessment procedure in this study.

This article is protected by copyright. All rights reserved. 
Figure 2. The trends in the proportion of deceased drivers with personality disorders (PDs) of all drivers killed in fatal motor vehicle collisions during 1990-2011 in Finland.

a) Deceased drivers with PD, by gender

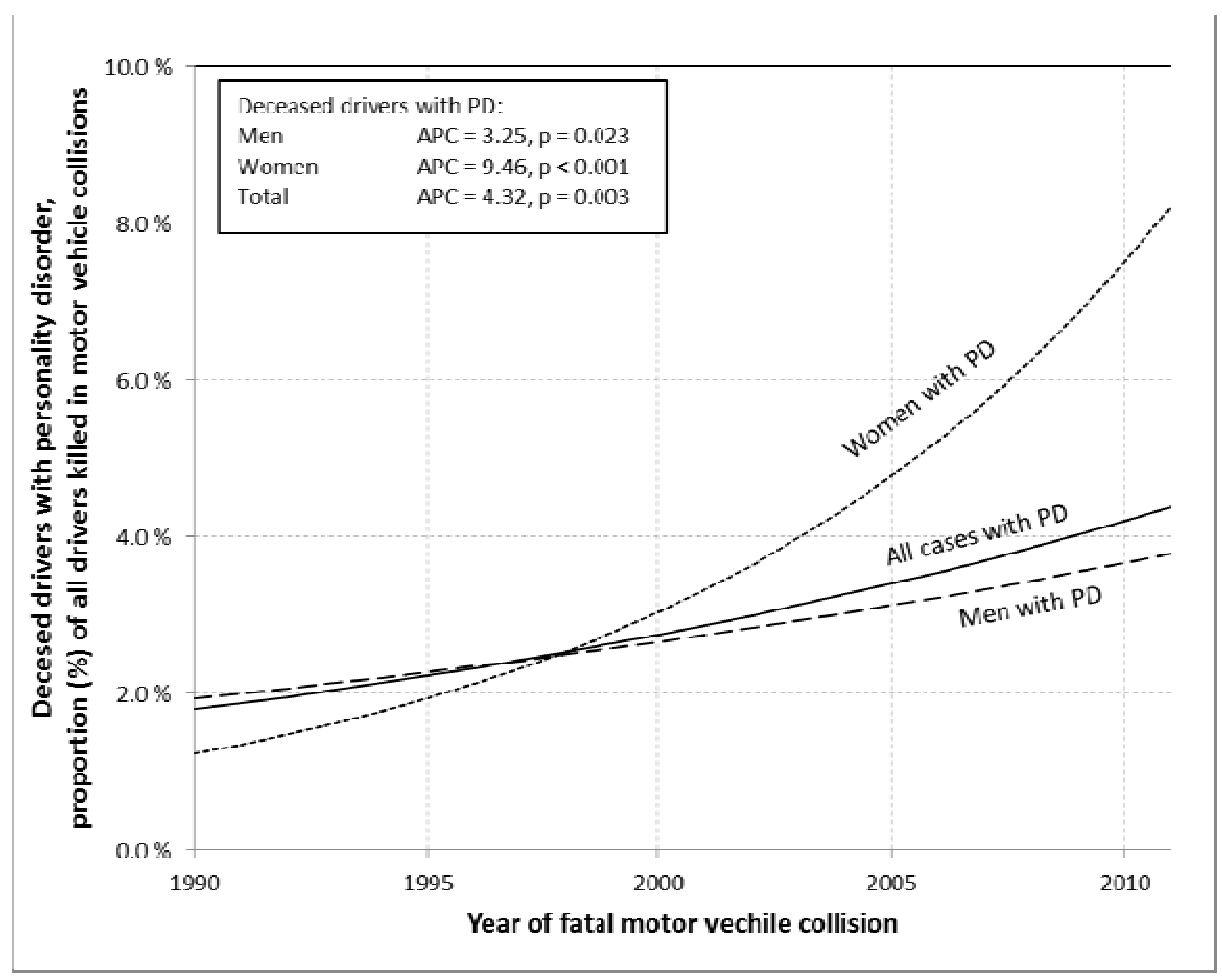

b) Deceased drivers with PD, by PD clusters 


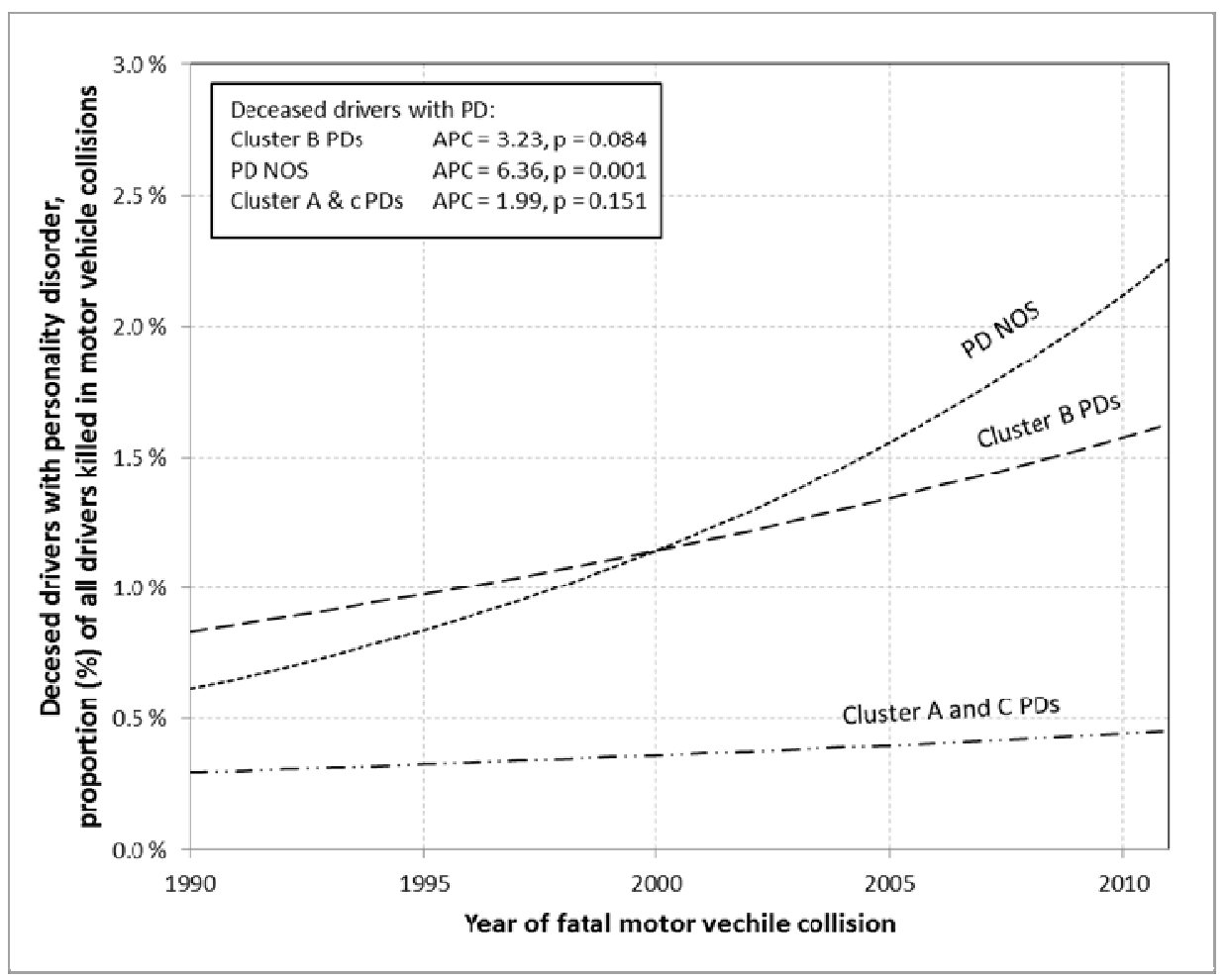

